\title{
The Ecology and Behaviour of Critically Endangered White- Rumped Vulture (Gyps Bengalensis) in and Around Jorbeer Area, Bikaner
}

\author{
Dr. Prabodh Chander Khatri \\ Lecturer (Biology), Department of Research, Institute of Advance Study in Education \\ (I.A.S.E.) Bikaner (Rajasthan) \\ prabodhchander@yahoo.com
}

\begin{abstract}
White-rumped vulture was completely migratory vulture at Jorbeer, Bikaner. Now it is disappearing from site. After year 2013 no single white-rumped was observed. Maximum of 7 white-rumped vultures recorded in 15 years of research study. The distribution of the species was recorded in 15 villages covering 1584 Square / Kilometer area between Latitude $27^{\circ} 50^{\prime}$ North to $28^{\circ} 04^{\prime}$ North and $73^{\circ} 04^{\prime}$ East to $73^{\circ} 34^{\prime}$ East Longitude as home range in Eastern-Southern and South-West part of Bikaner. The spectacular daily activity of white-rumped vulture comprises Feeding 2.72\%, Resting 67.42\%, Sunning 0.60\%, Scratching 0.05\%, Disturbance $0.06 \%$, Fighting $0.009 \%$ and Flight $27.87 \%$ of total day activity. Only one dead vulture and no sick vulture observed during research work. At Jorbeer, feral dogs are main threat for vultures. Medication and effect of any disease was not recorded in vultures.
\end{abstract}

Keywords: White-rumped vulture, Migratory, Disappearing, Feral dogs.

\section{INTRODUCTION}

Vultures have declined from many parts of their former ranges owing to food shortages and loss of habitat (Pain et al. 2003). Since the early 1990s there has been a catastrophic decline in three Gyps species in the Indian subcontinent white rumped vulture, long billed and slender billed vultures ${ }^{1}$. White-rumped vulture Gyps bengalensis was once abundant in south-East Asia and Indian subcontinent. In response it was classified as "Critically Endangered" placing them among the species most threatened with global extinction ${ }^{2}$. A large number of factors have contributed to the decline in vulture populations in southern Asia. Renal failure and visceral gout resulting from the consumption of livestock carcasses contaminated with the veterinary drug diclofenac are believed to be the main factors contributing to the large-scale and rapid decline of Gyps vultures. ${ }^{(3,10)}$

The white-rumped vulture (Gyps bengalensis) in an old world vulture closely related to the Eurassian griffon vulture (Gyps fulvus). At one time it was believed to be closes to whit-backed vulture of Africa and was known as the oriental white-backed vulture. The species was present in large numbers, in Southern and South Eastern Asia until the 1990s and declined rapidly in numbers since up to $99.9 \%$ between 1992 and $2007^{(4)}$.

This research study describes complete ecology and behavioural study of white-rumped vulture at Jorbeer and surrounding areas of Bikaner district.

\section{MATERIAL AND METHODS}

The study area "Jorbeer" is situated about $12 \mathrm{~km}$ in Eastern sight of Bikaner jorbeer and adjoining village areas represents the typical desertic conditions i.e. the extreme high and low temperature, low rainfall, excessive evaporation, high solar incidence, wind velocity, dust storm and frequent dune shifting. Jorbeer is a municipal dump as 20-35 carcasses dumped per day by Municipal Board. Now the area is conserved by forest department. The temperature reaches $49-50^{\circ} \mathrm{C}$ high and minimum $1^{0} \mathrm{C}$ to $-2^{0} \mathrm{C}$.

\section{RESUlTS AND DisCUSSION}

Seven vulture species have been recorded at Jorbeer ${ }^{(5)}$ i.e. Long billed vulture (Gyps indicus), white rumped vulture (Gyps bengalensis) Himalayan Griffon vulture (Gyps himalayensis), King vulture 
(Sarcogyps calvus), Cinereous vulture (Aegypius monachus) and Egyptian vulture (Neophron percnopterus). Nine species of vultures found in Indian subconitent ${ }^{(6)}$

\section{DISTRIBUTION OF WHITE-RUMPED VULTURE}

The white-rumped vulture breeds in East Pakistan, Nepal, India, South East Afghanistan, South East Iran and Bangladesh. It was formally also widely distributed in South-East Asia, but is now almost extinct there. It is sedentary, usually found in the lowlands (up to $1,000 \mathrm{~m}$ ) but exceptionally as high as $3100 \mathrm{~m}$.

\subsection{Descriptions}

\subsubsection{Adult Perched}

Mostly blackish plumage with slate-grey secondaries. At close range thin whitish streaks on underside and feathering medially on tibia. Base skin on head and neck rather dark brown-grey usually with a pink or maroon tinge to neck. Tarsus and toes medium to dark grey, claws blackish. Iris dark brown.

\subsubsection{Juvenile and Young Sub-adult Perched}

Gives an overall dark brown impression darks than any of the other species shows dark brown underside and feathering on lateral tibia, with rather clear cut thin whitish streaks; plain, dark brown mantle and scapulars, dark brown lesser and median coverts. Bill and Cere blackish in juvenile white top of upper mandible diffusely pale bluish-grey in young sub-adult.

\subsubsection{Habitat}

The vulture builds its nest on tall trees often near human habitations in northern and central India, Pakistan, Nepal and Southeast Asia, laying one egg. The Population is mostly resident. It is a scavenger feeding mostly from carcasses of dead animals which it finds by soaring high in thermals.

\subsubsection{Conservation Status}

Critically endangered (Fig.-1)

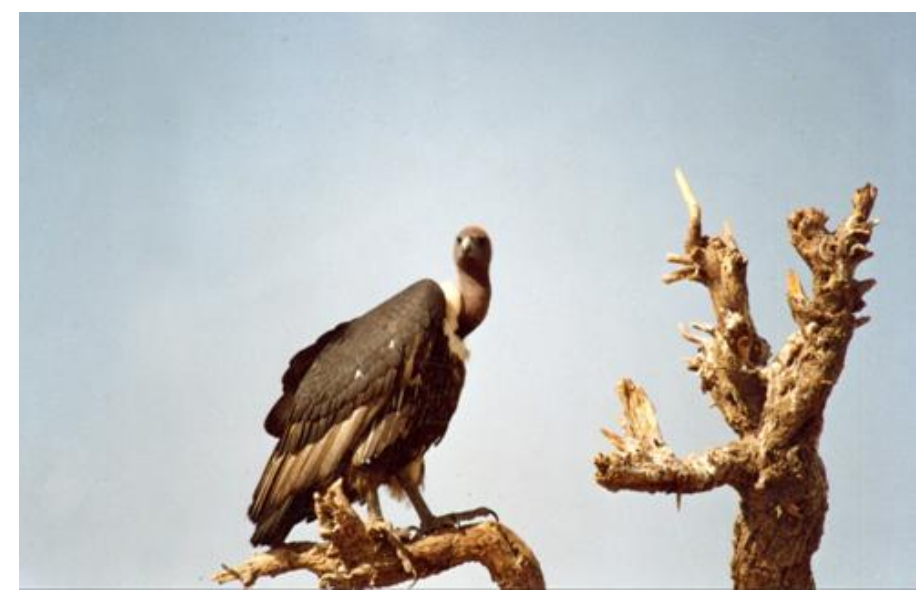

Figure1(a). Showing adult white-rumped Vulture (Gyps bengalensis) sitting on tree top at Jorbeer

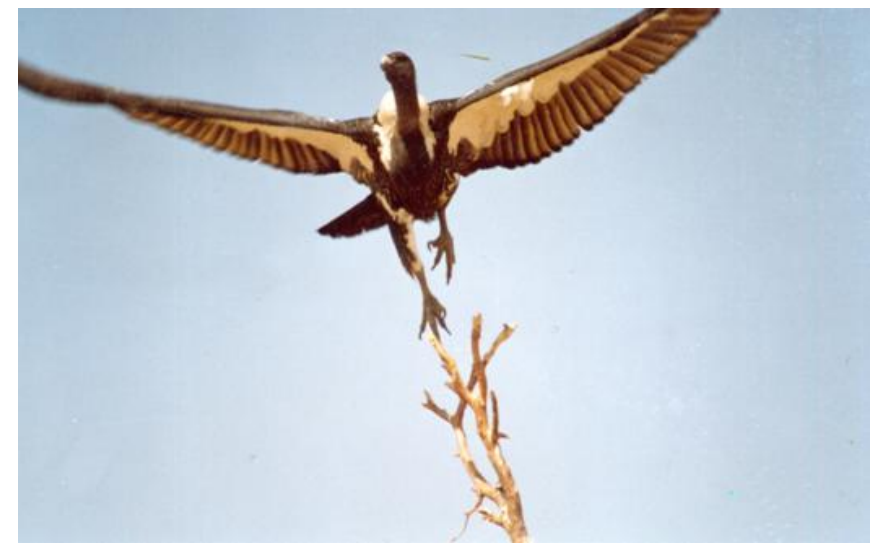

Figure1(b). Showing adult white-rumped Vulture (Gyps bengalensis) at take-off from tree top at Jorbeer 


\subsection{Population}

White-rumped vultures are migratory and visiting this area in winters. It arrive in September to November and upto first week of March they completely leave the area. The population of whiterumped vulture is very low at Jorbeer. The maximum of 4 white-rumped vultures in year 2000-2001, 2 vultures in 2001-2002, 6 vultures in 2002-2003, 7 vultures in 2003-2204, 6 vultures in 2004-2005, 4 vultures in 2005-2006, 4 vultures in 2006-2007, 6 vultures in 2007-2008, 4 vultures in 2008-2009, 5 vultures in 2009-2010, 3 vultures in 2010-2011, 2 vultures in 2011-2012 4 vultures in 2012-2012 were recorded. After year 2013 no single white-rumped vulture observed at Jorbeer ${ }^{(7)}$

\subsection{Home Range}

White-rumped vultures are distributed in 15 villages covering 1584 square / kilometer area between latitude $27^{\prime} 50^{\prime}$ north to $28^{\prime} 04$ north $73^{\prime} 04^{\prime}$ East to $73^{\prime} 34^{\prime}$ east as home range distributed in EasternSouthern and south-west part of Bikaner ${ }^{(8)(\text { Fig-2) }}$

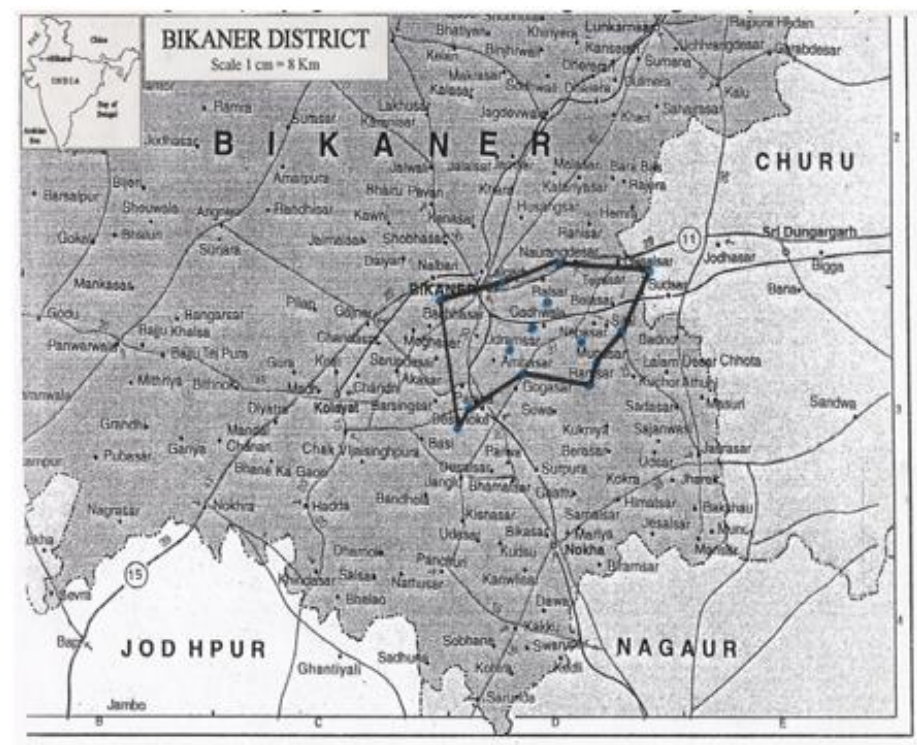

Fig2. Map: showing distribution and home range of White Backed vultures (Gyps bengalensis) staying at Bikaner District during winter migration (2000-2012)

\section{DAILY SCHEDULE OF ACTIVITY}

The daily activity of white-rumped vulture includes feeding, scratching, sunning, reaction to disturbance, flight and fight. This bird spends maximum time in resting and flight. Fighting comprises minimum time of its total activities, sunning and scratching occurs at some intervals. The observations about daily activities are as follows (Figure-2) -

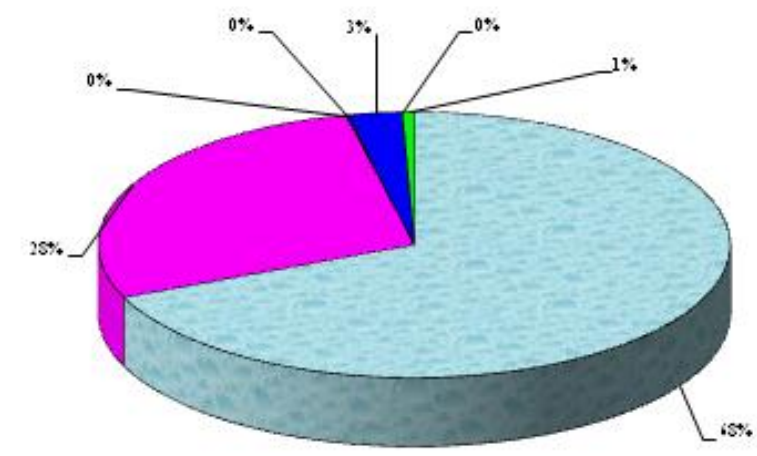

$\square$ Resting $\square$ Flight $\square$ Scratching $\square$ Disturbance $\mathbf{a}$ Feeding $\mathbf{a}$ Fighting $\square$ Surning

Fig2. White backed vulture (Gyps bengalensis) showing daily activities (resting, sunning, scratching, disturbance, feeding, fighting and flight) (in minutes) 


\subsection{Feeding}

Feeding is the most important activity comprising $2.72 \%$ of the total day activities. feeding was maximum between 11.00 hours to 12.00 hours. they were observed feeding with long billed vultures. It was seen to be dominated by cinereous and Griffon vultures. white-rumped vultures were observed to arrive late for feeding at carcasses particularly in last of all vultures.

\subsection{Resting}

It comprises $67.72 \%$ of the total day activities. It seems a lazy bird because it spends most of its time in resting. It was observed resting on ground or on trees along with long billied and Griffon Vultures.

\subsection{Sunning}

It comprises $0.60 \%$ of the total day activities sunning is done by the birds to get heat and warmth of body parts. During sunning they were seen to stretch neck and spread the wings fully. The back is kept toward the sun. White-rumped vultures continues sunning for 1-2 minutes receiving the first ray.

\subsection{Scratching}

It comprises $0.05 \%$ of total activities. The bird scratches the body parts with the help of its beak. Scratching continues for few seconds. It is done in older to remove pests or other material which causes irritation. scratching was observed during feeding and resting.

\subsection{Disturbance}

The white-rumped vultures are disturbed by large vultures like Himalayan Griffon, Eurasian Griffon and cinereous vultures during feeding. The disturbance comprises $0.06 \%$ of the total day activities. They were also seen disturbed by the sound of vehicles, man and by the barking of dogs.

\subsection{Fighting}

It comprises $0.009 \%$ of the total day activities activities. They were seen to fight with own members species and sometimes with long billed vultures during feeding.

\subsection{Flight}

The flight comprises $27.87 \%$ of the total day activities. Soaring was observed generally in afternoon It soars for hours at gut heights. The white rumped vultures generally do these activities after feeding.

\section{RESULTS AND DISCUSSION}

White-rumped at vulture have regularly wintered year 2001 to year 2013 maximum of 7 whiterumped vultures recorded in 13 years. After year 2013 no single white-rumped vulture has been observed in and around Jorbeer. The low population indicates that they are in trouble. Jorbeer area has plenty of food for survival of vultures and whole area is conserved. Recently a colony of 14 critically endangered long billed vultures and a chick with nest recorded in Khetoli village of Kolayat Tehsisl in Bikaner district on a 25 feet Khejri (Prosopis cineraria) tree ${ }^{(9)}$

Jorbeer area is spread in 56 square $\mathrm{km}$ and there are numbers of long and higher Khejri (Prosopis cineraria) trees, which provides nesting situating for vultures but whit-rumped vultures have not shown any sign of nesting or resident.

A large number of theories have suggested to contribute the decline in vulture populations in India and whole world. Renal failure and visceral gout resulting from the consumption of livestock carcasses contaminated with the veterinary drug diclofenac are believed to be the main factors contributing to large-scale and rapid decline gyps vultures $[3,10]$ In addition to diclofenac other veterinary drugs such as Ketoprofen and Acelofenac are known to be toxic to vultures. ${ }^{(11,12)}$

But vultures at Jorbeer have not exhibited overt sign of Dicloferac and Acelofenac contamination and toxicity. Even no single vulture was observed sick or diseased in 15 years of research study. Vultures well always injured and killed by feral dogs. ${ }^{(7)}$ Even Eurasian griffon vulture (Gyps fulvus) have increased consistently in past years at Jorbeer. The increase in Eurasian Griffons was related to livestock availability because the Feeding and roosting site both were close together at Jorbeer, indicates the high suitability of utilization of energy while reaching for food. ${ }^{(13)}$ Most of the vultures are winter migratory including Eurasian Griffon Vultures (Gyps fulvus). It arrives only in winters at Jorbeer. An adult Eurasian Griffon vulture recorded first time in summers at Jorbeer area. Survival of Eurasian Griffon vulture in $45^{\circ} \mathrm{C}-49^{\circ} \mathrm{C}$ temperature have shown sign of adaptation and tolerance to scorching heat of Thar desert and ensures its possibilities as resident vulture. 


\section{REFERENCES}

[1] Virani M., Gilbert M; Watson R., Oaks L., Benson P., Khan A., Baral H.S., and Giri J.B. PP 7-9 (2001). Asian Vulture Crises Project field results from Pakistan and Nepal for the (2000-2001) field season. In T. Katzner and J. Parry - Jones (eds). Reports from the workshop on Indian Gyps vultures, 4th Eurassian Congress on raptors, Sevilla, Spain, September 2001.

[2] White-rumped vulture (Gyps bengalensis)., Birdlife species factsheet (http://www.birdlife.org/datazone/speciesfactsheet.ppp?id=3374). Birdlife.org. Birdlife International. Retrieved 2011-06-01.

[3] Oaks J.L., Gilbert M., Virani M.Z., Watson R.T., Meteyer C.V., Rideout B.A., Shivaprasad H.L., Ahmed S., Chaudry M.J.L., Arshad M., Mahmood S., Ali A., Khan A.A. Diclofenac residues at the cause of vulture population decline in Pakistan. Nature 427 : 630-633 (2004).

[4] Prakash V., Pain D.J., Cunningham A.A., Donald P.F., Prakash N., Verma A., Gargi R., Shivkumar S and Rahamani A.R. Catastrophic collapse of Indian white-backed Gyps bengalensis and Long-billed Gyps indicus vulture populations. Biological conservation. 109 : 381-390 (2003).

[5] Katri P.C., Status of migratory vultures at Jorbeer, Bikaner (Rajasthan). Life Sciences Leaflets 1:6-13 (2013a).

[6] Ali S and Ripley S.D., Handbook of the Birds of India and Pakistan, compact edition, Oxford University Press, Bombay (1983).

[7] Khatri P.C., Vanishing vultures : All veterinary non-streoidal anti-inflammatory drugs (NSAIDS) Killing vulture ? A study at Jorbeer, Bikaner. International Journal of Pure and Applied Biosciences 3 (1) 217-223 (2015a).

[8] Khatri P.C., Home range use of winter migratory vultures in and around Jorbeer, bikaner (Rajasthan) India. Bioscience Discovery, 4 (1) : 96-99, Jan (2013b).

[9] Khatri P.C., First nesting of Critically endangered vultures in Bikaner. The nest site record of Long billed vulture (Gyps indicus) in Kilayat Tehsil, Bikaner. International Journal of Innovative Research and Revierw. 3 (2) : 8-13 (2015b).

[10] Green R.E., Taggart M.A., Das D., Pain D.J., Shashikumar C., Cunningham A.A., and Cuthbert R., Collapse of Asian vulture population : risk of mortality from residues of the veterinary drug diclofenac in carcasses of treated Cattle. Journal of Applied Ecology. 43 : 444-456 (2006).

[11] Sharma P., Acelofenac as a potential threat to critically endangered vultures in India : A Review Journal of Raptor Research 46 (3) : (2012)

[12] Naido V., Walker K., Cromarty D., Diekmann M. Toxicity of Non-steroidal anti-inflammatory drugs to Gyps Vultures : a new threat from Ketoprofen. Bio. Left. 6 : 339-341 (2010).

[13] Khatri P.C., The increase in the population of Eurassian Griffon Vultures (Gyps fulvus) at Jorbeer, Bikaner : Carcass dump as key habital for winter migration in the Griffon Vultures. International Journal of Geology. Earth and Environmental Sciences. 2(2) : 157-162 (2012).

[14] Khatri P.C., Survival of an adult Eurassian Griffon Vulture (Gyps fulvus) in summers at Jorbeer, Bikaner. International Journal of Pure \& Applied Sciences 3 (4) : 231-234 (2015b).

\section{AUTHOR's BIOGRAPHY}

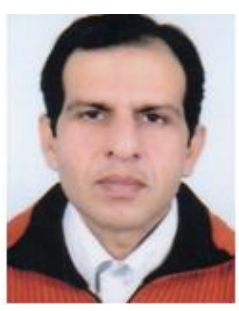

Dr. Prabodh Chander Khatri, is presently working as Lecturer (Biology) at Institute of Advance Study in Education (I.A.S.E.) Bikaner (Rajasthan). He has done his Ph.D. on Vultures on "Demography and Socio-ecology of Gyps Vultures at Bikaner" and worked on seven species of vultures. Dr. Khatri is M.Sc. (Zoology), M.Ed. and specilized in Environmental Sciences. He is conducting research on vultures and other raptors from the last fifteen years at Jorbeer, Bikaner and discovered this place in year 2000 which is international site for different Raptors now a days. He is member of Asian Raptor Research and Conversation Network (ARRCN). As a wildlife expert and Environmentalist Dr. Prabodh Chander Khatri is trying to conserve and save critically endangered species of vultures. 